\title{
HUBUNGAN PEMBELAJARAN PKn DENGAN PENGAMALAN \\ SILA PERSATUAN INDONESIA PESERTA DIDIK \\ SMP KEMBARAN 1 BANYUMAS
}

\author{
Oleh : \\ Tukiran Taniredja \\ Universitas Muhammadiyah Purwokerto \\ e-mail: tukiranump@gmail.com \\ Muhammad Abduh \\ Universitas Muhammadiyah Surakarta \\ e-mail:muhammad.abduh@ums.ac.id
}

\begin{abstract}
ABSTRAK
Tujuan penelitian untuk mengetahui proses pembelajaran PKn, pengamalan sila Persatuan Indonesia, dan hubungan pembelajaran PKn dengan pengamalan sila Persatuan Indonesia. Populasi penelitian seluruh peserta didik kelas 8F SMP Kembaran 1 Banyumas yang berjumlah 32. Seluruh populasi dijadikan sampel penelitian, sehingga merupakan sensus/sampel jenuh. Pengumpulan data dengan kuesioner tertutup. Analisis data dengan persentase dan korelasi product moment. Hasil analisis data menunjukkan proses pembelajaran PKn kuat (78\%), pengamalan Sila Persatuan Indonesia sangat kuat $(82 \%)$ dan tidak ada korelasi yang signifikan antara proses pembelajaran PKn dengan pengamalan sila Persatuan Indonesia, rxy $(0,21)$.
\end{abstract}

Kata Kunci: pembelajaran PKn, peserta didik, Sila Persatuan Indonesia 


\section{PENDAHULUAN}

Sangat terasa sekali bahwa semenjak digulirkan reformasi di negara kita, terdapat beberapa keprihatinan yang dirasakan tentang makna Pancasila bagi bangsa dan Negara Indonesia. Salah satunya Pancasila sebagai ideologi bermasyarakat, berbangsa, dan bernegara menjadi terpinggirkan. Dalam pidato-pidato resmi. para pejabat menjadi phobi dan malu untuk mengucapkan Pancasila. Anak-anak sekolah tidak lagi mengenal bunyi dan urutan Pancasila, apalagi nilai-nilai Pancasila. Bahkan kampus-kampus yang notabene sarat para cendekiawan pun berkembang kecenderungan untuk menafikan Pancasila. Tentunya kondisi yang demikian itu tidak bisa kita biarkan berlarut-larut.

Effendi ( 2006:2) Rektor UGM ketika membuka Kongres Pancasila tahun 2006 juga mengkritisi kondisi Pancasila pasca reformasi sebagai berikut," Sejak gerakan reformasi digulirkan dari kampus-kampus di tanah air, nampak berkembang kecenderungan untuk menafikan Pancasila sebagai ideologi dalam kehidupan kebangsaan dan kenegaraan kita. Walaupun UndangUndang No. 20 tahun 2003 tentang sistem Pendidikan Nasional tetap mencantumpan ideologi dasar Pancasila sebagai dasar Pendidikan nasional, peraturan pelaksanaannya tidak lagi mencantumkan pendidikan ideology Negara dalam kurikulum pendidikan nasional. Akibat dari penghapusan tersebut sangat mengkhawatirkan. Proses "colonialization of the mind" secara tidak disadari menjadi semakin marak dan pendidikan tinggi yang "Salah Asuan" berlangsung tanpa hambatan, menghasilkan para liulusan yang lebih menghayati paradigma ilmu pengetahuan milik budaya bangsa lain daripada ilmu pengetahuan yang berakar dari budaya bangsa sendiri”.

Menanggapi dan mengomentari Pancasila sebagai dasar Negara Republik Indonesia, As'ad (2010: ix) menyatakan bahwa para pendiri negara kita dengan sangat cemerlang mampu menyepakati pilihan yang pas tentang dasar negara sesuai dengan karakter bangsa, sangat orisinal, menjadi sebuah negara modern yang berkarakter religius, tidak sebagai negara sekuler juga tidak sebagai negara agama. Rumusan konsepsinya benar-benar diorientasikan pada dan sesuai dengan karakter bangsa. Mereka bukan hanya mampu menyingkirkan pengaruh gagasan negara patrimonial yang mewarnai sepanjang sejarah nusantara prakolonial, namun juga mampu meramu berbagai pemikiran politik yang berkembang saat itu secara kreatif sesuai dengan kebutuhan masa depan modern anak bangsa. 
Tokoh muda Latif ( 2011:2) juga menandaskan bahwa Pancasila adalah warisan dari jenius nusantara. Sesuai dengan karakteristik lingkungan alamnya, sebagai negeri lautan yang ditaburi pulau-pulau (archipelago), jenius Nusantara juga merefleksikan sifat lautan. Sifat lautan adalah menyerap dan membersihkan, menyerap tanpa mengotori lingkungannya. Sifat lautan juga dalam keluasannya, mampu menampung segala keragaman jenis dan ukuran.

Melemahnya semangat sila Persatuan Indonesia atau wawasan kebangsaan kita, disebabkan oleh beberapa permasalahan antara lain (1) kualitas SDM masih rendah; (2) militansi bangsa yang mendekati titik kritis; (3) jati diri bangsa Indonesia yang sudah luntur. Menghadapi berbagai permasalahan tersebut, apabila tidak ada upaya yang sungguh-sungguh, tidak menutup kemungkinan disintegrasi bangsa dapat menjadi ancaman aktual yang berpengaruh terhadap integritas dan kedaulatan NKRI (Santoso, 2008:67).

Wawasan kebangsaan Indonesia akhir-akhir ini memang mengalami ujian yang cukup berat. Ikatan-ikatan yang sebelumnya terpatri kuat dalam sebuah titik pandang sama dalam sebuah nation, kini berkembang dalam kesadaran etnis sempit yang terus meningkat dan merongrong kewibawaan kebangsaan yang dibangun lebih dari lima puluh tahun yang lalu oleh para founding father/mother kita. Bahkan kesadaran etnis tersebut telah mengakibatkan sentimen berlebihan dengan tuntutan merdeka dari beberapa daera (Jalil, A.2003:v).

Rasa nasioalisme, cinta tanah air, sila Persatuan Indonesia, khususnya di negara kita harus tetap kita pertahankan, karena di era global ini ada kecenderungan dunia bergerak ke arah seribu negara, menjadi negara-negara kecil dengan asumsi bahwa mensejahterakan rakyat yang sedikit akan lebih mudah daripada mensejahterakan rakyat yang banyak.

Dengan sila Persatuan Indonesia, manusia Indonesia menempatkan persatuan, kesatuan serta kepentingan dan keselamatan bangsa dan negara di atas kepentingan pribadi atau golongan. Menempatkan kepentingan negara dan bangsa di atas kepentingan pribadi bahwa manusia Indonesia sanggup dan rela berkorban untuk kepentingan negara dan bangsa. Oleh karena sikap rela berkorban untuk kepentingan bangsa dan negara itu dilandasi oleh rasa cinta kepada tanah air dan bangsanya maka dikembangkanlah rasa kebanggaan berkebangsaan dan bertanah air Indonesia.

Persatuan dikembangkan atas dasar Bhinneka Tunggal Ika, dengan memajukan pergaulan demi persatuan dan kesatuan bangsa. Dalam rangka mencapai perdamaian 
dunia atas dasar kemerdekaan, perdamaian abadi, dan keadilan sosial maka hubungan antar bangsa didasarkan pada prinsip saling menghormati dan bekerja sama.

Secara historis, pendidikan memegang peranan yang sangat penting dalam menumbuhkan kesadaran kebangsaan atau nasionalisme pada bangsa Indonesia. Pendidikan pada saat ini, masih tetap diharapkan memainkan peran strategis dalam membinakan dan meningkatkan nilai-nilai Pancasila dan nilai-nilai sila Persatuan Indonesia kepada generasi muda (Maftuh, 2008)..

Asumsi dasar menjadikan sila Persatuan Indonesia menjadi tumpuan eksistensi suatu nation-state adalah bahwa eksistensi suatu nation state menuntut adanya suatu culture core yang disepakati bersama yang mewujudkan kisi-kisi di dalam mana berbagai subkultur dapat berinteraksi dan beraktualisasi. Dan sila Persatuan Indonesia merupakan bentuk culture core yang mengikat berbagai subkultur tadi dalam satu kesatuan entitas politik. Sila Persatuan Indonesia bukan produk peristiwa instant, akan tetapi berkembang dalam pengalaman sejarah suatu bangsa. Ernest Renan, dalam bukunya Qu'est ce qu'une Nation melihat bahwa hakikat sila Persatuan Indonesia adalah le dessire vivre ensemble (keinginan untuk hidup bersama ) atau le desire d'etre ensemble (keinginan untuk eksisit bersama). Sila Persatuan Indonesia bertumpu pada kesadaran akan adanya jiwa dan prinsip spiritual ,yang berakar pada kepahlawanan masa lalu, dan tumbuh karena penderitaan bersama, dan kesenangan bersama. Kesamaan historis masa lampau telah terbentuk kesadaran sejarah untuk tetap berada bersama dalam entitas politik di masa depan. Hal ini menuntut penghayatan etos pluralisme di satu pihak, menghargai eksistensi dan hak eksisi berbagai subkultur untuk vivre ensemble dan d'etre ensemble ( Tjokrowinoto,1998:40).

Sila kebangsaan mengandung prinsip persatuan Bangsa Indonesia yang tidak sempit, karena prinsip ini mengandung pengakuan bahwa setiap bangsa bebas menentukan nasibnya sendiri tanpa campur tangan satu sama lain.

Berdasarkan uraian di atas permasalahan yang muncul adalah bagaimanakan pembelajaran PKn di sekolah, bagaimanakah pengamalan sila Persatuan Indonesia dan adakah hubungan antara pembelajaran PKn dengan pengamalan sila Persatuan Indonesia di kelas 8F SMP Kembaran 1 Banyumas.

\section{KAJIAN PUSTAKA Pembelajaran PKn}

Cogan dalam (Winarno, 2014: 71) menyatakan bahwa pembelajaran PKn merupakan proses pendidikan secara utuh dan menyeluruh terhadap pembentukan 
karakter individu sebagai warga negara yang cerdas dan baik.

Kaitannya dengan PKn di Indonesia, Kosasih Djahiri dalam (Winarno, 2014: 71) menyatakan bahwa pembelajaran PKn adalah program pendidikan yang secara programatik prosedural berupaya memanusiakan (humanizing) dan membudayakan (culturing) serta memberdayakan (empowering) menusia / anak didik (diri dan lingkungannya) menjadi warga negara yang baik dalam Negara Kesatuan Republik Indonesia.

Rahmat dkk.,(2013: 21) menyatakan bahwa pembelajaran PKn dapat membekali siswa dengan pengetahuan dan keterampilan intelektual yang memadai serta pengalaman praktis agar memiliki kompetensi dan efektivitas dalam berpartisipasi.

\section{Sila Persatuan Indonesia}

Bung Hatta sangat mengharapkan terwujudnya "persatuan", bukan "persatean". Kita memiliki lebih dari 750 suku bangsa, suku bangsa-suku bangsa ini sebagai pemangku Nusantara yang pada tanggal 17 Agustus 1945 kita satukan bersama dalam satu "persatuan" menjadi bangsa Indonesia. "Persatuan" seluruh bangsa ini hanya akan menjadi "persatean" apabila tidak kita tumbuhkan satu "ruh" yang sama dalam Gemeinschaft. Satu ruh kebersamaan itu adalah Pancasila. Ketika Bung Karno pada tanggal 1
Juni 1945 menyampaikan pidatonya di depan BPUPKI yang berjudul "Lahirnya Pancasila" Bung Hatta ibarat menemukan apa yang dicarinya sebagai "ruh" persatuan bangsa yang bhinneka ini. Oleh karena itu Pancasila dapat diterima sebagai ruh berbangsa dan bernegara, sebagai "asas bersama" yang tunggal bagi yang bhinneka agar menjadi tunggal ika (Swasono, 2014:9).

Persatuan, menurut Hatta (dalam Swasono, 2014: 8) adalah adanya "persatuan hati" yang membuat kita "berdiri sebaris". Lama setelah itu, dengan senang hati Hatta menyambut lahirnya Pancasila 1 Juni 1945 sebagai dasar "persatuan hati", sebagai "ruh ideologi kebersamaan dan asas kekeluargaan" yang senantiasa ia perjuangkan. Bahkan pada saat Bung Hatta berbeda pendapat keras dengan Bung Karno tahun 1960, Bung Hatta tetap memegang teguh Pancasila yang disebutnya sebagai "filsafat negara Indonesia" yang dilahirkan oleh Soekarno. Saya (Swasono) kutipkan pandangan Hatta yang mulia, halus pekerti, ideologis dan religious sebagai berikut ini," ... dengan dasar-dasar ini sebagai pimpinan dan pegangan pemerintah Negara pada hakekatnya tidak boleh menyimpang dari jalan yang lurus untuk mencapai kebahagiaan rakyat dan keselamatan masyarakat, perdamaian dunia serta persaudaraan bangsa-bangsa. Dengan bimbingan dasar-dasar yang tinggi dan murni itu akan dilaksanakan 
tugas yang tidak dapat dikatakan ringan! Manakala kesasar sewaktuwaktu dalam perjalanan, karena kealfaan atau digoda hawa nafsu, ada terasa senantiasa desakan gaib yang membimbing kembali ke jalan yang benar ...demikian harapan kaum idealis yang merumuskan filsafat Negara dan Undang-Undang Dasar Negara Republik Indonesia dalam saat yang bersejarah, yang menentukan nasib bangsa. Satu ciptaan, mungkin terlalu tinggi bagi manusia biasa melaksanakannya, tetapi sebagai pegangan untuk menempuh jalan yang baik sangat diperlukan. Dasar-dasar itu menuntut kepada manusia Indonesia, kepada pemimpin-pemimpin politik dan kepada orang-orang Negara untuk melatih diri, supaya sanggup berbuat baik dan jujur, sesuai dengan janji yang diperbuat di muka Tuhan...".

Pada tanggal 28 Oktober 1928 para pemuda Indonesa melalui Sumpah Pemuda telah mengikrarkan kebhinekaan menjadi "putusan Kongres Pemuda-Pemudi Indonesia", yang kemudian terkenal dengan Sumpah Pemuda yang isinya: (1). Kami Putra-putri Indonesaia mengaku bertumpah darah yang satu, tanah Indonesia; (2). Kami Putraputri Indonesaia mengaku berbangsa yang satu, bangsa Indonesia; (3) Kami Putra-putri Indonesia, menjunjung bahasa persatuan, Bahasa Indonesia.

Pancasila sebagai pemersatu bangsa maksudnya sebagai alat persatuan dan kesatuan yang di dalamnya merumuskan langsung cita-cita bangsa Indonesia dalam bernegara yaitu mewujudkan keadilan sosial bagi seluruh rakyat Indonesia. Cita-cita atau tujuan Negara ini dapat menyatukan semua sub sistem dalam sistem sosial yang ada (Bakry, 1997:48).

Bangsa Indonesia yang beraneka ragam suku dan kebudayaan, dengan ideologi Pancasila dapat hidup serasi, persatuan dan kesatuan bangsa dapat dijaga. Negara Indonesia yang berdasarkan Pancasila bertujuan untuk mewujudkan masyarakat adil dan makmur yang merata material dan spiritual berdasarkan nilai-nilai Pancasila.

$$
\text { Smith (2003 }
$$

mendefinisikan bahwa nasionalisme adalah suatu ideologi yang meletakkan bangsa di pusat masalahnya dan berupaya mempertinggi keberadaannya.

Nasionalisme Indonesia mengandung makna bahwa bangsa Indonesia tidak lebih rendah dari bangsa penjajah, akhirnya semangat tersebut melahirkan gerakan-gerakan perlawanan terhadap kolonialisme. Hal tersebut ditandai mulai dari berdirinya budi utomo sebagai organisasi pada era kebangkitan nasional yang kemudian melahirkan semangat persatuan, sampai proklamasi kemerdekaan Indonesia (Alfaqi, 2015). 
Nationalism, the most potent principle of political legitimacy in the modemworld, holds that the nation should be collectively and freely institutionally expressed, and ruled by its co-nationals. Recent events demonstrate nationalist movements retain the capacity to shake states and empires, as well as the pieties of devout conservatives and cosmopolitan liberals and socialists. Ernest Gellner's writings aimed to explain why nationalism has become the key principle of political legitimacy of our times. In numerous essays and three books this fluent, prolific and witty philosopher, anthropologist, sociologist and multi-lingual polymath provided lucid and persuasive accounts of why nationalism is a necessary component of modernity and why it is the most salient principle of political legitimacy (O’leary, 1997).

$$
\text { Naisbitt }
$$

menjelaskan lebih lanjut bahwa tribalisme tidak boleh dikacaukan dengan sila Persatuan Indonesia yang berkembang sejak abad ke- 19 dan merupakan suatu kepercayaan bahwa negara bangsa (nation-state) seseorang lebih penting daripada prinsip intersila Persatuan Indonesia atau pertimbangan individual. Tribalisme adalah kepercayaan pada sesama jenisnya sendiri, yang didefinisikan oleh etnisitas, bahasa, budaya, agama, atau pada abad ke-20 ini profesi. Media "The Economist" secara serius mengingatkan bahwa "virus tribalisme" mempunyai resiko menjadi AIDS dalam politik internasional - tinggal tidur selama bertahun-tahun, kemudian meruyak untuk menghancurkan negaranegara.

The term nationalism is as controversial as its etymological and historical roots nationalism is a theory, an ideology, a movement, a consciousness and a creed; but it is also a disease, an expression of mania. Its meaning in. each of these categories is not less diverse nor is the categories explicitly defined. (204). Nationalism is the sense of political togetherness that makes people feel patriotic about a country, connected to a 'we-group', and distinct from 'they-group'. As an Ideology, nationalism holds that the nation should be the primary political identity of individuals (Negedu, 2015).

Nasionalisme adalah suatu paham yang berpendapat bahwa kesetiaan yang tertinggi harus diserahkan pada negara kebangsaan . Perasaan sangat mendalam dalam suatu ikatan yang erat dengan tanah tumpah darahnya, dengan tradisitradisi setempat dan penguasapenguasa resmi di daerahnya selalu ada di sepanjang sejarah dengan kekuatan-kekuatan yang berbedabeda. Akan tetapi baru pada akhir abad-18 Masehi nasionalisme dalam arti kata modern menjadi suatu perasaan yang diakui secara umum. 
Dan nasionalisme ini makin lama makin kuat peranannya dalam membentuk semua bagi kehidupan baik yang bersifat umum maupun bersifat pribadi .Dan baru di masa akhir-akhir ini syarat bahwasanya setiap bangsa harus membentuk suatu negaranya, negaranya sendiri, dan bahwa negara itu harus meliputi seluruh bangsa. Dahulu kesetiaan seseorang tidak ditunjukkan kepada negara kebangsaan, melainkan berbagai macam bentuk kekuasaan sosial, organisasi politik dan atau ideologi seperti misalnya suku atau clan, negara kota atau raja feodal, kejayaan , gereja, dinasti, atau golongan keagamaan. Berabad-abad lamanya cita dan tujuan politik bukanlah negara kebangsaan , melainkan , setidak-tidaknya dalam teori imperium yang meliputi seluruh dunia, melingkungin berbagai bangsa dan golongan-golongan etnis di atas dasar peradaban yang sama serta menjamin perdamaian bersama ( Kohn, 1984:11)

Bentuk nasioalisme Indonesia tidak semuanya meniru dari nasionalisme Indonesia yang ada di negara-negara Barat. Tidak bisa dipungkiri bahwa nasionalisme lahir sebagai alat gerakan perlawanan terhadap kolonialisme dan imperialisme.akan tetapi pada dasarnya nasionalisme terlahir karena adanya politik identitas serta solidaritas, yaitu sebuah rasa bahwa bangsa Indonesia pernah mempunyai peradaban yang besar. seperti kerajaan Sriwijaya dan Majapahit dari berbagai peninggalan yang berupa bangunan-bangunan misalnya candi sampai peninggalan nilai-nilai luhur yang pernah ada di Nusantara (Alfaqi, 2015).

Sebagai ideologi, nasionalisme dapat memainkan tiga fungsi, yaitu mengikat semua kelas, menyatukan mentalitas mereka, dan membangun atau memperkokoh pengaruh terhadap kebijakan yang ada di dalam kursi utama ideologi nasional (Hertz, dalam Karim, 1996:101)\}.

Nasionalisme melalui facisme di Italia dan Jerman menentang liberalisme pada tahun 1930-an, walaupun dikalahkan oleh liberalisme pada Perang Dunia II. Facisme sendiri gagal bertahan karena tidak mempunyai doktrin universal seperti liberalisme dan komunisme. Ia menolak keberadaan kemanusiaan bersama atau persamaan hak-hak manusia, dan juga terlalu mengagungkan ras dan bangsa sebagai sumber legimitasi terutama masters race seperti bangsa Jerman untuk memerintah rakyat (Fukuyama, dalam Karim, 1996: 101)..

In its most basic sense, ethnicity refers to the social reproduction of basic classifica-tory differences between categories of people and to aspects of gain and loss in social interaction. Ethnicity is fundamen-tally dual, encompassing aspects of both meaning and politics. 
Ethnicity is, however, a concept which refers to a multitude of sociocultural phenomena. It may appear at our door-step any time and vanish in a matter of seconds: for instance, my relation-ship with foreign students at the university has ethnic connotations and can thus be viewed as an ethnic relationship. They enter my office and go away; the duration of such an ethnic relationship can be less than half an hour ( Eriksen, 1991).

Bung Karno ketika berpidato di depan sidang pertama BPUPKI tanggal 1 Juni 1945 menguraikan tentang makna Kebangsaan Indonesia, bahwa bangsa Indonesia, natie Indonesia, bukanlah sekedar satu golongan orang yang hidup dengan "le desir d'entre ensemble" di atas daerah yang kecil seperti Minangkabau, atau Madura, atau Yogya, atau Sunda, aau Bugis, tetapi bangsa Indonesia ialah seluruh manusia-manusia yang menurut geopolitik yang telah ditentukan Allah SWT, tinggal di kesatuannya semua pulau-pulau Indonesia dari Ujung Sumatera sampai Irian! Seluruhnya! (Ana, Singgih Hawibowo, dan Agus Wahyudi, 2006 : 105).

Menurut Notonagoro (1983: 65) inti sila Persatuan Indonesia dapat dirumuskan, kesadaran akan adanya perbedaan-perbedaan di dalam masyarakat dan bangsa, menghidup-hidupkan perbedaan yang mempunyai daya penarik ke arah kerja sama dan kesatuan, dan mengusahakan peniadaan serta pengurangan perbedaan yang mungkin mengakibatkan suasana dan kekuatan tolak-menolak ke arah perselisihan, pertikaian dan perpecahan atas dasar kesadaran akan kebijaksanaan dan nilai-nilai hidup yang sewajarnya, lagi pula dengan kesediaan, kecakapan dan usaha untuk sedapat-dapatnya melaksanakan pertalian kesatuan kebangsaan, mungkin menurut pedoman-pedoman majemuk tunggal bagi pengertian kebangsaan.

Menurut P4 (Pedoman Penghayatan dan Pengamalan Pancasila) dengan sila Persatuan Indonesia hendaknya manusia Indonesia menempatkan persatuan, kesatuan, serta kepentingan dan keselamatan Bangsa dan Negara di atas pribadi dan golongan. Menempatkan kepentingan Negara dan Bangsa di atas kepentingan pribadi, berarti bahwa manusia Indonesia sanggup dan rela berkorban untuk kepentingan Negara dan Bangsa, apabila diperlukan. Oleh karena sikap rela berkorban untuk kepentingan Negara dan Bangsa itu dilandasi oleh rasa cinta kepada Tanah Air dan Bangsanya, maka dikembangkanlah rasa kebangsaan berkebangsaan dan bertanah air Indonesia, dalam rangka memelihara ketertiban dunia yang berdasarkan kemerdekaan, perdamaian abadi dan keadilan sosial. Persatuan dikembangkan atas dasar Bhinneka 
Tunggal Ika, dengan memajukan pergaulan demi kesatuan dan persatuan Bangsa.

Pedoman Penghayatan dan Pengamalan Pancasila, memberikan pedoman kepada Bangsa Indonesia untuk mengamalkan sila Persatuan Indonesia secara lebih rinci yaitu (a) mampu menempatkan persatuan, kesatuan, serta kepentingan dan keselamatan bangsa dan negara sebagai kepentingan bersama di atas kepentingan pribadi atau golongan; (b) sanggup dan rela berkorban untuk kepentingan bangsa dan negara apabila diperlukan; (c) mengembangkan rasa cinta kepada tanah air dan bangsa; (d) mengembangkan rasa kebanggaan berkebangsaan dan bertanah air Indonesia; (e) memelihara ketertiban dunia yang berdasarkan kemerdekaan, perdamaian abadi dan keadilan sosial; (f) mengembangkan Persatuan Indonesia atas dasar Bhinneka Tunggal Ika; dan (g) memajukan pergaulan demi persatuan dan kesatuan bangsa.

\section{METODE PENELITIAN}

Penelitian ini merupakan penelitian deskriptif kuantitatif. Penelitian dilaksanakan di kelas $8 \mathrm{~F}$ SMP Kembaran 1 Banyumas pada bulan Maret s.d Juni 2017. Populasi Penelitian peserta didik kelas $8 \mathrm{~F}$ SMP Negeri Kembaran 1 Banyumas sebanyak 32 orang. Semua populasi dijadikan sampel sehingga merupakan penelitian sensus/sampel jenuh.

Pengumpulan data yang digunakan adalah angket. Angket yang digunakan angket tertutup yaitu jawaban telah tersedia sehingga responden tinggal memilih salah satu di antara jawaban yang sesuai dengan pendapat masing-masing.

Pengukuran menggunakan

skala likert karena skala Likert digunakan untuk mengukur sikap, pendapat dan persepsi seseorang atau sekelompok orang tentang fenomena sosial. Persekoran jawaban angket seperti tabel di bawah ini:

Tabel 1

Pensekoran jawaban angket Jawaban Angket

\begin{tabular}{|l|l|}
\hline Alternatif Jawaban & Skor \\
\hline Selalu & 5 \\
\hline Sering & 4 \\
\hline Kadang-kadang & 3 \\
\hline Jarang & 2 \\
\hline Tidak pernah & 1 \\
\hline
\end{tabular}


Analisis Data

Teknik analisis data untuk mengetahui pembelajaran PKn dan pengamalan nilai-nilai Sila I digunakan teknik persentase. Analisis dilakukan persentase secara keseluruhan. Rumus yang digunakan sebagai berikut:

$$
\%=\frac{F o}{f n} \times 100 \quad \begin{aligned}
& \%=\text { persentase } \\
& f o=\text { frekuensi yang ditemukan } \\
& f n=\text { frekuensi maksimal } \\
& (\text { Sugiyono,2016:134) }
\end{aligned}
$$

Untuk memudahkan dan dipergunakan pengelompokan menyeragamkan dalam pengambilan persentase sebagai berikut:

penafsiran dan kesimpulan, maka

$$
\begin{array}{ll}
0 \%-20 \% & \quad \text { : sangat lemah } \\
21 \%-40 \% & : \text { lemah } \\
41 \%-60 \% & : \text { cukup } \\
61 \%-80 \% & : \text { kuat } \\
81 \%-100 \% & \text { : sangat kuat (Riduwan, 2013:89) }
\end{array}
$$

Untuk mengetahui hubungan Indonesia digunakan statistik antara pembelajaran PKn dan Korelasi Product Moment, dengan pengamalan Sila Persatuan rumus sebagai berikut:

$$
r_{x y}=\frac{N \sum x y-\left(\sum x\right)\left(\sum y\right)}{\sqrt{\left.\left\{N \sum x^{2}-\left(\sum x^{2}\right)^{2}\right\} N \sum y^{2}-\left(\sum y\right)^{2}\right\}}}
$$

(Arikunto, 2006). 


\section{HASIL PENELITIAN DAN PEMBAHASAN \\ Hasil Penelitian}

Hasil pengisian angket yang dilakukan responden seperti tabel di bawah ini:

Tabel 1

Hasil Angket Pembelajaran PKn dan Pengamalan SilaPersatuan Indonesia

\begin{tabular}{|c|c|c|c|c|c|c|c|c|}
\hline No & $\mathbf{X}$ & $\mathbf{Y}$ & $\mathbf{N o}$ & $\mathbf{X}$ & $\mathbf{Y}$ & $\mathbf{N o}$ & $\mathbf{X}$ & $\mathbf{Y}$ \\
\hline $\mathbf{1 .}$ & 91 & 23 & $\mathbf{1 2 .}$ & 66 & 26 & $\mathbf{2 3 .}$ & 89 & 33 \\
\hline $\mathbf{2 .}$ & 56 & 31 & $\mathbf{1 3 .}$ & 85 & 30 & $\mathbf{2 4 .}$ & 87 & 33 \\
\hline $\mathbf{3 .}$ & 69 & 30 & $\mathbf{1 4 .}$ & 74 & 18 & $\mathbf{2 5 .}$ & 88 & 33 \\
\hline $\mathbf{4 .}$ & 66 & 31 & $\mathbf{1 5 .}$ & 83 & 27 & $\mathbf{2 6 .}$ & 86 & 27 \\
\hline $\mathbf{5 .}$ & 85 & 26 & $\mathbf{1 6 .}$ & 74 & 32 & $\mathbf{2 7 .}$ & 81 & 35 \\
\hline $\mathbf{6 .}$ & 89 & 29 & $\mathbf{1 7 .}$ & 70 & 20 & $\mathbf{2 8 .}$ & 77 & 30 \\
\hline $\mathbf{7 .}$ & 86 & 33 & $\mathbf{1 8 .}$ & 86 & 24 & $\mathbf{2 9 .}$ & 94 & 27 \\
\hline $\mathbf{8 .}$ & 94 & 29 & $\mathbf{1 9 .}$ & 74 & 34 & $\mathbf{3 0 .}$ & 37 & 23 \\
\hline $\mathbf{9 .}$ & 77 & 30 & $\mathbf{2 0 .}$ & 68 & 28 & $\mathbf{3 1 .}$ & 64 & 23 \\
\hline $\mathbf{1 0 .}$ & 79 & 31 & $\mathbf{2 1 .}$ & 71 & 35 & $\mathbf{3 2 .}$ & 79 & 26 \\
\hline $\mathbf{1 1 .}$ & 86 & 30 & $\mathbf{2 2 .}$ & 83 & 32 & & & \\
\hline
\end{tabular}

Kererangan:

$\mathrm{X} \quad$ : skor pembelajaran PKn

Y : skor pengamalan sila Persatuan Indonesia

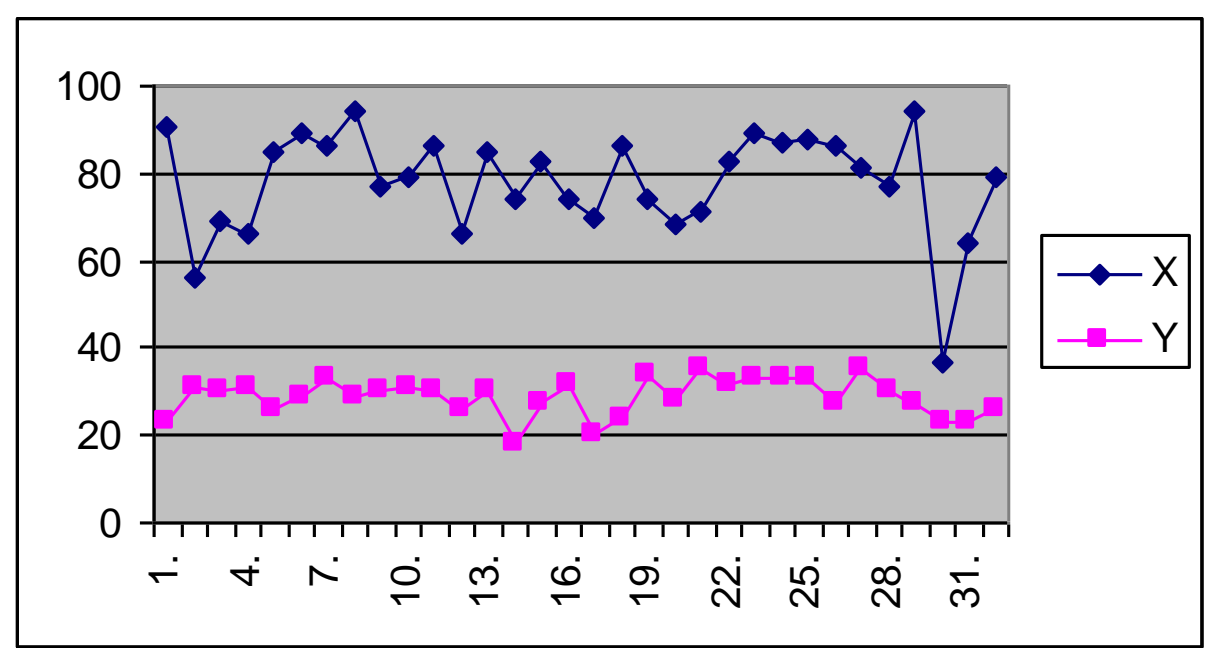

Gambar 1. Grafik Hubungan Pembelajaran PKn dengan Pengamalan Sila Persatuan Indonesia

Hasil analisis data presentase didapatkan hasil untuk pembelajaran $\mathrm{PKn}=2.500:(32 \times 5 \times 20) \times 100 \%$ $=78 \%$. Sedangkan pengamalan sila
Persatuan Indonesia $=919:(32 \times 5 \times$ 7) $\mathrm{x} 100 \%=82 \%$. Sedangkan hasil analisis data hubungan antara pembelajaran PKn dengan 
pengamalan sila Persatuan Indonesia

diperoleh angka rxy 0,21 .

Hasil pembelajaran PKn

$0,78 \%$. Pengamalan sila III

Pancasila $82 \%$ ini menunjukkan bahwa proses pembelajaran PKn sudah kuat, dan pengamalan sila Persatuan Indonesia sangat kuat. Hasil analisis hubungan antara pembelajaran PKn dan pengamalan sila Persatuan Indonesia diperoleh angka rxy 0,21 berarti pembelajaran PKn belum begitu banyak menyadarkan peserta didik untuk mengamalkan sila Persatuan Indonesia, atau tidak ada hubungan significan antara pembelajaran PKn dengan pengamalan sila Persatuan Indonesia.

\section{Pembahasan}

Berdasarkan hasil analisis data proses pembelajaran PKn sudah kuat, dan pengamalan sila Persatuan Indonesia bagi peserta didik sangat kuat, tetapi tidak ada hubungan yang significan antara pembelajaran PKn dengan pengamalan Sila Persatuan Indonesia. Ini menunjukkan bahwa pembelajaran PKn di kelas baru menekankan pada ranah kognitif. Sedangkan dua ranah lainnya yakni afektif dan psikomotorik masih belum banyak mendapatkan perhatian. Pembelajaran masih sangat menekankan pada pengetahuan semata. Ini merupakan kesalahan besar bagi guru-guru PKn yang seharusnya pembelajaran PKn lebih menekankan pada ranah afektif.

$\begin{array}{cr}\text { PKn dalam } & \begin{array}{r}\text { praktek } \\ \text { hendaknya }\end{array}\end{array}$
mengutamakan pengembangan ranah afektif. Hal ini sesuai dengan kurikulum pendidikan dasar dan menengah tahun 1994, dikenal dengan Pendidikan Pancasila dan Kewarganegaraan, yang diartikan sebagai mata pelajaran yang digunakan sebagai wahana untuk mengembangkan dan melestarikan nilai luhur dan moral, yang berakar pada budaya bangsa Indonesia. Nilai luhur dan moral tersebut diharapkan dalam bentuk perilaku kehidupan sehari-hari peserta didik, baik sebagai individu maupun sebagai anggota masyarakat, dan makhluk ciptaan Tuhan Yang Maha Esa. Perilaku yang dimaksud adalah sesuai dengan Pancasila dan UndangUndang Dasar Negara Republik Indonesia Tahun 1945 yaitu perilaku yang bersifat kemanusiaan yang adil dan beradab, perilaku yang mendukung persatuan dan kesatuan yang mengutamakan kepentingan bersama di atas kepentingan perorangan dan golongan, sehingga perbedaan pemikiran, pendapat ataupun kepentingan diatasi melalui musyawarah dan mufakat, serta perilaku yang mendukung upaya untuk mewujudkan keadilan sosial bagi seluruh rakyat Indonesia (Depdikbud, 1996:1).

Perilaku-perilaku yang dimaksudkan di dalam Pendidikan Pancasila dan Kewarganegaraan tersebut sesuai dengan pasal 3 
Undang-Undang Republik Indonesia Nomor 20 Tahun 2003 tentang Sistem Pendidikan Nasional yang menandaskan bahwa pendidikan nasional berfungsi mengembangkan kemampuan dan membentuk watak serta mencerdaskan kehidupan bangsa, bertujuan untuk berkembangnya potensi peserta didik agar menjadi manusia yang beriman dan bertakwa kepada Tuhan Yang Maha Esa, berakhlak mulia, sehat, berilmu, cakap, kreatif, mandiri, dan menjadi warga negara yang demokratis serta bertanggung jawab. Oleh karena itu pembelajaran PKn jika sekedar menstransfer ilmu pengetahuan/kognitif, berarti pembelajaran PKn masih Belem berhasil.

Pada umumnya guru dalam mengajar masih menggunakan metode pembelajaran ceramah. Bukan berarti metode ceramah tidak baik. Metode ceramah menjadi kurang baik apabila dalam pembelajaran PKn didominasi dengan metode caramah. Seharusnya pembelajaran PKn dilakukan secara kritis, analitis melalui dialog-kreatif dan bersifat partisipatoris agar tumbuh kesadaran berbangsa dan bernegara secara rasional dan untuk meyakini kebenaran serta ketepatan konsepsi bela negara dalam aplikasi pandangan hidup bangsa.

Selama ini metode pengajaran yang diterapkan dalam mata pelajaran PKn nilai intinya kebanyakan masih merupakan proses indoktrinasi yang hanya menyentuh aspek kognisi, sedangkan aspek sikap dan perilaku belum tersentuh, sehingga pembelajaran masih belum beranjak dari paradigma pendidikan sebagai transfer of knowledge semata.

Hal ini sesuai dengan Pasal 5 Surat Keputusan Dirjen Dikti No.38 Tahun 2002, Dirjen Dikti Depdiknas (2002:4), menegaskan bahwa dalam metodologi pembelajaran mata kuliah pengembangan kepribadian (MPK) hendaknya : pendekatan : menempatkan mahasiswa sebagai subjek pendidikan, mitra dalam proses pembelajaran, dan sebagai umat, anggota keluarga, masyarakat dan warga negara; metode proses pembelajaran pembahasan secara kritis analitis, induktif, deduktif dan reflektif melalui dialog kreatif yang bersifat partisipatoris untuk meyakini kebenaran subtansi dasar kajian; bentuk aktifitas proses pembelajaran : kuliah tatap muka secara bervariasi, ceramah, dialog kreatif (diskusi) interaktif, metode inquiry, study kasus, penugasan mandiri, seminar kecil, dan berbagai kegiatan akademik lainnya yang lebih menekankan kepada pengalaman belajar peserta didik secara bermakna; dan motivasi: menumbuhkan kesadaran bahwa pembelajaran pengembangan kepribadian merupakan kebutuhan hidup.

Pengamalan sila Persatuan Indonesia bagi peserta didik sudah 
sangat kuat. Hal ini bisa saja diperoleh para peserta didik di luar proses pembelajaran PKn seperti membaca buku-buku, film, media massa, atau diperoleh di masyarakat seperti peringatan hari-hari besar nasional dan peristiwa-peristiwa lain yang terkait dengan pengamalan sila Ketiga Pancasila.

Pengalaman-pengalaman

peserta didik dalam hal pengamalan Sila Ketiga Pancasila dapat diperoleh dari berbagai hal. Oleh karenanya kita berikan penguatan agar peserta didik banyak membaca buku-buku, melihat film-film perjuangan/ kepahlawanan dan ikut berpartisipasi aktif dalam perayaan hari-hari besar nasional.

\section{SIMPULAN DAN SARAN}

Berdasarkan analisis data dapat disimpulkan bahwa proses pembelajaran PKn sudah kuat , pengamalan sila Persatuan Indonesia sangat kuat dan tidak ada korelasi yang signifikan antara proses pembelajaran PKn dengan pengamalan sila Persatuan Indonesia pada peserta didik kelas 8F SMP 1 Kembaran Banyumas.

Saran yang diajukan, guru PKn dalam mengajar hendaknya menggunakan pendekatan pembelajaran yang berpusat pada peserta didik, bukan sekedar transformasi ilmu tetapi berupaya pembelajaran yag bersifat penyadaran, senantiasa dikaitkan dan ditekankan dengan nilai-nilai Pancasila dan kewarganegaraan, termasuk juga nilai Sila Persatuan Indonesia dan lebih menekankan pada aktualisasi/pengamalan dalam kehidupan sehari-hari. Di samping itu guru dalam mengajar bukan hanya menekankan aspek kognitif, tetapi harus lebih menekankan aspek afektif dan psikomotor. Peserta didik dibiasakan untuk membaca buku, melihat film perjuangan dan kepahlawanan, serta ikut berpartisipasi dalam peringatan harihari besar nasional.

\section{DAFTAR PUSTAKA}

\section{Buku}

Ana,I.D.,Singgih H., dan Agus W., (ed), 2006. Pemikiran Para Pemimpin Negara tentang Pancasila Yogyakarta: Aditya Media.

Arikunto, 2006. Prosedur Penelitian Suatu Pendekatan Praktik, Jakarta : Rineka Cipta.

As'ad, A.S., 2010. Negara Pancasila Jalan Kemaslahatan Berbangsa, Jakarta, LP3ES.

Bakry, N.,M., 1985. Pancasila Yuridis Kenegaraan, Yogyakarta: BPFH UII. 
Kohn, H., 1984. Nasionalisme Arti dan Sejarahnya terjemahan Sumantri Mertodipuro, Jakarta : Erlangga.

Latif, Y., 2011. Negara Paripurna, Historitas, Rasionalitas, dan Aktualitas Pancasila, Jakarta: PT Gramedia.

Naisbitt, J., 1994. Global Paradox, New York : William Morrow and Company, Inc.

Notonagoro, 1983. Dasar Falsafah Negara, Jakarta: PT Bina Aksara.

O'leary,1997. On the Nature of Nationalism: An Appraisal of Ernest Gellner's Writings on Nationalism, B.J.Pol.S. 27, 191-222 Copyright Ó , Cambridge UnVIersity Press: Printed in Great Britain.

Rahmat dkk.,2013. Pembelajaran Pendidikan Kewarganegaraan. Bandung: Laboratorium Pendidikan Kewarganegaraan.

Riduwan, 2013. Belajar Mudah Penelitian. Bandung: Alfabeta.

Smith., A.,D., 2003. Nasionalisme Teori Ideologi Sejarah, Jakarta: Erlangga.

Sugiyono, 2016. Metode Penelitian Pendidikan: Pendekatan Kuantitatif, Kualitatif, dan $R \& D$. Bandung: Alfabeta.

Swasono., S. E., 2014. Kebangsaan, Kerakyatan dan Kebudayaan, Yogyakarta: UST-Press.

Winarno, 2014. Pembelajaran Pendidikan Kewarganegaraan. Jakarta: PT Bumi Aksara.

\section{Artikel dalam Buku Kumpulan Artikel}

Djalil, A. M.,2003 Menemukan Kembali Kebangsaan Indonesia, dalam M.Bambang Pranowo dan Darmawan (Ed), Reorientasi Wawasan kebangsaan di Era Demoakrasi, Yogyakarta : AdicitaKarya Nusa.

\section{Artikel dalam Jurnal}

Alfaqi, M.Z., 2015. Memahami Indonesia Indonesia melalui Prespektif Nasionalisme, Politik Identitas, serta Solidaritas, Jurnal Pendidikan Pancasila dan Kewarganegaraan, Th. 28, Nomor 2, Agustus 2015

Karim, R. 1996. Nasionalisme Arti dan Sejarahnya, Jurnal Analisis, XXV: 2, CSIS: 95-108.

Maftuh, B., 2008. Internalisasi Nilai-Nilai Pancasila dan Nasionalisme Melalui Pendidikan Kewarganegaraan, Educationist, Vol. II No. 2 Juli 2008.

Nagedu, Isaiah; 2015. Nationalism in Nigeria: A Case for Patriotic Citizenship, American International Journal of Contemporary Research Vol. 5, No. 3; June 2015,

Tjokrowinoto, M., 1998.. Nasionalisme dalam Prespektif Politik, Jurnal Filsafat Pancasila II (2) Pusat Studi Pancasila UGM : 37-46. 


\section{Dokumen Resmi}

Departemen Pendidikan Nasional, (2002). Kurikulum 2004 SMA Pedoman Khusus Pengembangan Silabus dan penilaian Mata Pelajaran Kewarganegaraan . Jakarta : Direktorat Jenderal Pendidikan Dasar dan menengah Direktorat Pendidikan Menengah Umum.

Direktur Jenderal Pendidikan Tinggi Departemen Pendidikan Nasional Republik Indonesia Nomor: 43/DIKTI/Kep/2006 tentang Rambu-rambu Pelaksanaan Kelompok Matakuliah Pengembangan Kepribadian di Perguruan Tinggi.

\section{Makalah Seminar}

Effendi, S, 2006. Sambutan pada 'Simposium Nasional Pengembangan Pancasila sebagai Paradigma Ilmu Pengetahuan dan Pembangunan Nasional.

Santoso, Dj., 2008. Ketahanan Negara dan Wawasan kebangsaan Menghadapi Tantangan Global, Makalah disampaiakan pada Simposium Nasional Peringatan Satu Abad Kebangkitan Nasional, 19 Mei 2008, Yogyakarta : UGM, Pemda DIY, Kagama. 